\title{
Saber da experiência e narrativas autobiográficas na formação inicial de professores de biologia
}

\section{The wisdom of experience and autobiographical narratives in pre-service education of biology teachers}

\author{
Maria Luiza de Araújo Gastal ${ }^{1}$. Maria Rita Avanzi ${ }^{1}$
}

\begin{abstract}
Resumo: $\mathrm{O}$ artigo trata da produção de narrativas na formação de alunos de Licenciatura em Ciências Biológicas da Universidade de Brasília, à luz das ideias de Larrosa sobre saber da experiência e tendo, como referencial metodológico de pesquisa, as narrativas autobiográficas. As narrativas estudadas foram produzidas em duas disciplinas, e indicam uma autorreflexão dos licenciandos sobre seu percurso de formação desde estudante de Educação Básica até sua vivência no estágio supervisionado. Os elementos que orientam as reflexões aqui desenvolvidas destacam: o papel da subjetividade na formação do professor; o ato de narrar como facilitador de uma autocompreensão; e o papel das narrativas autobiográficas como metodologia de pesquisa e formação de professores.
\end{abstract}

Palavras-chave: Ensino de Biologia. Narrativas autobiográficas. Formação de professores. Reflexão.

\begin{abstract}
This paper deals with the production of narratives by students on the biology education teachers' undergraduate program at Universidade de Brasilia, in the light of the ideas of Larrosa about the wisdom of experience as well as the methodological and empirical framework of autobiographical narratives. The narratives were produced in two undergraduate courses and show how the students could make a self-reflection about their journey to become a teacher, from their past as students of basic education to their experience in the supervised training courses. The elements that guide the reflections highlight the role of subjectivity in teacher education, the act of narration as a facilitator of self-understanding and the role of autobiographical narratives as a research methodology and as an instrument of teacher training.
\end{abstract}

Keywords: Biology teaching. Autobiographical narratives. Teacher training. Reflection.

\footnotetext{
${ }^{1}$ Instituto de Ciências Biológicas, Núcleo de Educação Científica, Universidade de Brasília (UnB), Campus Universitário Darcy Ribeiro, Asa Norte, 70910-900, Brasília, DF, Brasil. E-mail: <malugastal@gmail.com>
} 


\section{Introdução}

A estrutura curricular do curso de Licenciatura em Ciências Biológicas da Universidade de Brasília, além de disciplinas pedagógicas oferecidas pela Faculdade de Educação, contempla quatro disciplinas de formação específica que são oferecidas pelo Núcleo de Educação Científica do Instituto de Ciências Biológicas (NECBio). Duas delas, chamadas de Metodologia do Ensino de Ciências (MEC) e Metodologia do Ensino de Biologia (MEB), buscam contextualizar diferentes abordagens de ensino, visando preparar os estudantes para a prática, por meio de uma reflexão sobre os pressupostos teórico-metodológicos do ensino de ciências e biologia, do planejamento e execução de atividades didáticas simuladas, e da elaboração de materiais didáticos.

Os Estágios Supervisionados em Ensino de Ciências (ESEC) e de Biologia (ESEB) objetivam a inserção do discente na realidade educacional das escolas públicas do Distrito Federal por meio da prática docente. Neste artigo, desenvolveremos reflexões a partir de material produzido pelos alunos nas disciplinas de MEB e ESEC.

Nas duas disciplinas, utilizamos a produção de narrativas pelos licenciandos como caminho reflexivo da prática docente e, portanto, para a formação desses futuros professores. Tal opção metodológica está presente em diversos trabalhos sobre formação de professores, em especial, a partir da década de 1980, quando se abre espaço para o encontro entre as dimensões pessoais e profissionais, permitindo, aos professores, apropriarem-se dos seus processos de formação e darem a esses processos um sentido no quadro das suas histórias de vida (NÓVOA, 1995).

Ao interpretarmos as narrativas produzidas pelos licenciandos em trabalho anterior (GASTAL et al., 2010), identificamos elementos que sustentam a importância dessa atividade autonarrativa para sua formação:

- A produção da narrativa permite emergir aspectos da subjetividade que, à medida que dão sentido à experiência vivida, contribuem para a formação do professor.

- O ato de contar para outro proporciona a reconstrução da experiência formativa do autor e contribui para sua autocompreensão.

- Narrar em primeira pessoa dá abertura para a emergência de aspectos criativos e reflexivos; com isso, o ato de narrar tem repercussões sobre a qualidade da reflexão desenvolvida.

Neste artigo, tratamos da produção de narrativas como elemento de reflexão sobre o percurso de formação de alunos de Licenciatura em Ciências Biológicas da Universidade de Brasília. Tais narrativas foram produzidas em duas disciplinas, à luz das ideias de Larrosa (2011) sobre saber da experiência, e tendo, como referencial metodológico de pesquisa e formação, as narrativas autobiográficas (FINGER, 2010; JOSSO, 2010a, 2010b; NÓVOA, 1995). Buscamos, também, trazer contribuições para a compreensão do papel das narrativas autobiográficas como metodologia de investigação e de formação.

\section{Saber da experiência e formação docente}

A base conceitual para desenvolver os três elementos identificados nas narrativas dos estudantes reconhece o saber da experiência (LARROSA, 2003, 2011) como faceta fundamental do saber docente. Considera, também, o papel que esse autor atribui ao ato de narrar para outro como fator que permite uma reflexividade crítica no percurso formativo. 
A noção de saber da experiência é concebida, nas palavras de Larrosa, como "o que se adquire no modo como alguém vai respondendo ao que lhe vai passando ao longo da vida e que vai conformando o que alguém é” (LARROSA, 2011, p. 14).

$\mathrm{O}$ autor nos apresenta o saber da experiência como um saber finito, por estar relacionado ao amadurecimento do indivíduo em particular, e como idiossincrático, pois ainda que dois sujeitos enfrentem o mesmo acontecimento, não fazem a mesma experiência. Por não se separar do indivíduo concreto, portanto, não é um conhecimento que esteja fora do sujeito, e "só tem sentido no modo como configura uma personalidade" (LARROSA, 2011, p.14). Não se constitui, assim, em mera atividade cognitiva.

O saber da experiência é, ao mesmo tempo, subjetivo e social. Subjetivo porque, como assinalado, é idiossincrático e vivido a partir do atravessamento do sujeito social pela experiência particular, como sugere Larrosa (2011, p. 7):

[...] o lugar da experiência é o sujeito ou, dito de outro modo, que a experiência é sempre subjetiva. [...] o "princípio da subjetividade" supõe também que não há experiência em geral, que não há experiência de ninguém, que a experiência é sempre experiência de alguém ou, dito de outro modo, que a experiência é, para cada um, a sua, que cada um faz ou padece sua própria experiência, e isso de um modo único, singular, particular, próprio.

Ressaltamos que o saber da experiência, tal como aqui tratado, vai além da noção de "conhecimento tácito", apontada por Schon (1983 apud PIMENTA, 2008, p. 19) como conhecimento que está na ação, mobilizado no dia a dia docente, e que se configura como hábito. Esse seria o saber da prática. A partir de Larrosa, compreendemos que a prática pode ser vivenciada sem que seja assumida como experiência. A experiência pressupõe que o acontecimento, como algo que vem de fora, afete o sujeito, produza efeitos no que é, no que pensa, no que sente, no que sabe. Essa abertura da experiência como proposta por Larrosa $(2003,2011)$ também a diferencia daquela experiência descrita por Mizukami et al. (2002, p. 50), que é utilizada como uma forma de "confirmar, mais do que [...] contrariar, colocar em xeque ou mesmo desafiar nosso pensamento". A reflexão envolvida na experiência, neste sentido, vai além do cotejamento da prática com a teoria. Teoria e prática são, assim, tratadas na relação com o sujeito da experiência.

Esse aspecto revela, portanto, a natureza também social do saber da experiência e a importância do ato de narrar para outro na constituição de uma autocompreensão.

A autocompreensão narrativa não se produz em reflexão não mediada sobre si mesmo, mas neste gigantesco caldeirão de histórias que é a cultura e em relação à qual organizamos nossa própria experiência (o sentido do que nos passa) e nossa própria identidade (o sentido de quem somos). (LARROSA, 2003, p. 28, tradução nossa)

\section{Narrativas e saber da experiência}

Adicionalmente, os três elementos identificados nas narrativas dos estudantes (GASTAL et al., 2010) justificam o uso da abordagem autobiográfica como método de pesquisa e de forma- 
ção. O primeiro elemento destaca a importância da subjetividade para a tomada de consciência e apropriação do processo formativo pelo sujeito aprendente. Relaciona-se com o conceito de reflexividade crítica (NÓVOA, 1995), que postula que o sujeito adulto forma-se enquanto reconstrói e atribui sentidos a sua vida. Ainda que as narrativas autobiográficas sejam utilizadas com o intuito de obter dados para pesquisas, seu papel formativo é reconhecido e enfatizado pelos autores aqui considerados (FERRAROTI, 2010; JOSSO, 2010a, 2010b; NÓVOA, 1995).

Cabe destacar, ainda, que compreendemos reflexão não como algo que resulta somente de um processo psicológico individual, mas como uma atividade contextualizada, historicamente, na produção de conhecimento (PIMENTA, 2008) e, sobretudo, como resultado de um movimento em que sujeito da experiência se deixe tocar por ela, implicando uma saída para algo que ocorre fora dele e um retorno para o sujeito. Esse é um dos aspectos onde identificamos um diálogo próximo entre as ideias de Larrosa e dos autores que trabalham com a perspectiva autobiográfica.

Um movimento de ida porque a experiência supõe um movimento de exteriorização, de saída de mim mesmo [...] E um movimento de volta porque a experiência supõe que o acontecimento afeta a mim, que produz efeitos em mim, no que eu sou, no que eu penso, no que eu sinto, no que eu sei, no que eu quero etc. (LARROSA, 2011, p. 7)

A subjetividade e a reflexividade crítica relacionam-se, também, ao segundo pressuposto - o ato de contar para outro proporciona a reconstrução da experiência formativa do sujeito e contribui para sua autocompreensão. Como ressalta Bueno (2002), a biografia é uma microrrelação social que traz implícita uma intencionalidade comunicativa - aquele que narra sua história de vida sempre narra para alguém. Para Ferraroti (2010), esse caráter, aliado à compreensão de que o contexto histórico-social é apropriado pelo sujeito da narrativa em sua história singular, marca o aspecto heurístico do método biográfico. Conforme enfatizamos anteriormente, os aspectos subjetivo e social do saber da experiência são indissociáveis. À medida que se manifesta nas relações complexas entre professores e alunos, tal saber se dá na interface entre o individual e o social, entre o ator e o sistema (TARDIF, 2000).

Josso (2010a, p. 39) também reconhece o papel do contexto sociocultural na formação. Esse contexto, na tensão dialética com a dimensão individual, resulta na aprendizagem experiencial, um meio de elaboração e integração do "saber-fazer e dos conhecimentos". Para a autora, o processo narrativo permite um reconhecimento, pelos sujeitos que narram, das escolhas feitas a partir daquilo que aprenderam experiencialmente ao longo da vida, nesse tensionamento com os aspectos históricos. Novamente, um encontro com as ideias de Larrosa apresentadas anteriormente.

[...] esse modo de reconsiderar o que foi a experiência oferece a oportunidade de uma tomada de consciência do caráter necessariamente subjetivo e intencional de todo e qualquer ato de conhecimento, e do caráter eminentemente cultural dos conteúdos dessa subjetividade, bem como da própria idéia de subjetividade. (JOSSO, 2010a, p. 41) 
O terceiro elemento, a respeito do processo criativo implicado no ato de narrar, também fundamenta-se em Josso (2010b) que, ao descrever o método da narrativa autobiográfica para a formação, assinala que, inicialmente, a maioria dos sujeitos preocupa-se com a objetividade e exaustividade dos relatos. É no decurso do processo que eles vão tomando consciência de que tal objetividade é impossível e desnecessária, "visto que se trata de conhecer e compreender os significados que cada um atribui ou atribuiu em cada período da sua existência aos acontecimentos e situações que viveu" (JOSSO, 2010b, p. 68).

\section{Narrativas autobiográficas como metodologia de pesquisa}

Pineau (2006, p. 240) caracteriza a narrativa autobiográfica "como um meio pessoal maior, e talvez incontornável, do exercício em um círculo diferente do 'curvar-se (fechar) reflexivo e desdobrar-se (abrir) narrativo"”, diferenciando essa forma de obtenção de informações das narrativas biográficas, que são intermediadas por um terceiro, que se constitui o narrador.

A riqueza desta forma de abordagem reside, dentre outros aspectos, no fato de que as narrativas autobiográficas fazem emergir momentos da história de vida dos professores, que evidenciam elementos de sua cultura e formação que podem ser examinados pelo pesquisador (GALVÃO, 2005). Ainda que não permitam, evidentemente, um acesso direto à experiência vivida pelos sujeitos, as narrativas oferecem ao pesquisador uma possibilidade de interpretação dos sentidos atribuídos pelo narrador à experiência. Desta forma, o conhecimento que resulta deste tipo de pesquisa "serve de lente interpretativa da compreensão da experiência de cada um” (GALVÃ̃, 2005, p. 330), e assume a subjetividade como objeto de estudo e categoria analítica na formação de professores (BUENO, 2002).

Ao mesmo tempo, considerando que permite um movimento reflexivo do narrador sobre a experiência, essa abordagem se aproxima da perspectiva formativa tratada anteriormente, uma vez que abre a possibilidade de os sujeitos da pesquisa se tornarem "parceiros na produção de significados" e na reflexão sobre a experiência narrada (CUNHA; CHAIGAR, 2009, p. 121). Ao ser capaz deste segundo movimento de produção de novos significados, o narrador deixa de se constituir num mero informante, para, também, assumir o papel de pesquisador de sua própria ação. Temos, assim, a inseparabilidade entre as dimensões da formação e da pesquisa ao fazermos uso das narrativas autobiográficas.

\section{Metodologia}

A recolha de informações ocorreu em duas disciplinas do curso de Licenciatura em Ciências Biológicas da Universidade de Brasília (UnB), entre 2008 e 2011: Metodologia do Ensino de Biologia (MEB) e Estágio Supervisionado no Ensino de Ciências (ESEC).

Em MEB, os estudantes produzem um texto reflexivo em primeira pessoa, que relaciona sua experiência como aluno e docente em formação às leituras teóricas realizadas na disciplina.

Em ESEC, produzem um relato, também em primeira pessoa, na forma de um diário a ser entregue em intervalos de três semanas (seis cadernos, no total), no qual devem refletir sobre a experiência da disciplina como um todo: a observação, a monitoria e a regência na escola, as aulas de supervisão na Secretaria de Educação do Distrito Federal, e os debates travados com os colegas, enfim, qualquer experiência significativa. 
No total, 251 estudantes cursaram as duas disciplinas no período considerado, e são os textos resultantes dessas duas atividades o material de análise deste trabalho.

A partir da leitura desse material, elencamos recortes que indicam uma autorreflexão sobre o percurso dos licenciandos em sua formação.

\section{Resultados}

Conforme explicitado anteriormente, as narrativas serão apresentadas tendo como eixo os três elementos trazidos na introdução deste artigo. O primeiro deles reconhece o papel da narrativa na atribuição de sentidos à experiência vivida. Neste artigo, "experiência vivida" referese tanto à experiência dos sujeitos como estudantes em todo seu percurso na educação básica quanto àquela que atravessou em sua formação universitária, inclusive em seu estágio docente.

As narrativas escritas pelos estudantes sugerem que, no decorrer da graduação, vivenciam um reconhecimento gradual de que estão em um curso de formação de professores, sobre o qual passam a tomar consciência a partir das disciplinas de Metodologia de Ensino, cursadas no NECBio. Ainda que cursem o que chamam de "disciplinas pedagógicas" na Faculdade de Educação, anteriormente às do NECBio, é perceptível certa resistência dos licenciandos a se apropriarem delas como parte de sua formação, talvez por se projetarem mais como futuros biólogos do que como futuros professores.

Havia me formado uma profissional ciente da minha responsabilidade como cientista, mas apática quanto a minha responsabilidade como professora. MEB, tanto no seu aspecto teórico quanto no seu aspecto prático, literalmente "abriu meus olhos" para o universo da docência, antes visto por mim como um ônus da carreira acadêmica. [Joana, MEB] $]^{2}$

O exercício de produção de narrativas em MEB, cujo propósito é relacionar a experiência à teoria estudada, possibilita revisitar momentos vividos como alunos de Educação Básica em uma perspectiva diferente, agora em busca de elementos para sua futura atuação como professores.

Quando eu estava na $5^{a}$ série do ensino fundamental, existia em minha escola um projeto em que os alunos cultivavam uma pequena horta. Em uma das primeiras visitas à horta, um colega meu, que ficou responsável por fazer os buracos onde seriam colocadas as mudas, fez um buraco muito profundo e quando a muda foi colocada, ela "sumiu" pra dentro do solo. Em virtude disso, minha turma não participou mais do Projeto Horta. Com essa atitude, o professor fez. com que perdêssemos a oportunidade de aprendizado que teríamos com o projeto, sendo que ele poderia ter explorado o "erro" do meu colega, nos perguntado o que ocorreria com a muda, por que ela não vingaria etc., colocando-nos como agentes no cultivo da horta, mostrando que nossas açoes fariam diferença no sucesso dela. [Lúcia, MEB]

\footnotetext{
${ }^{2}$ Os nomes dos alunos são fictícios. São seguidos pela sigla da disciplina em que a narrativa foi produzida.
} 
Nesta narrativa, vemos o sujeito num lugar de passagem, onde começa a observar sua experiência como estudante à luz das teorias e daquilo que o espera logo à frente: a docência nos Estágios Supervisionados. É recorrente que os aspectos privilegiados, sejam eles técnicos ou teóricos, assumam um tom de crítica ao que o narrador considera uma falha na prática de seus professores.

Pude vivenciar este tipo de experimentação diversas vežes durante o Ensino Fundamental e Médio, em que realizávamos atividades puramente seguindo protocolos, sem mesmo entender o que estava sendo testado. Esse tipo de atitude acaba tornando essas atividades monótonas e sem sentido, aniquilando o sentimento de excitação que os alunos sentiam incialmente, quando elas eram propostas. [Maria, MEB]

Nos dois trechos, vemos que a narrativa de sua experiência como estudante tem como referência para a prática docente a teoria que conheceu nas disciplinas formativas, que é percebida como ausente ou insuficiente em seus professores, mas desejável no professor que projeta ser. Tais narrativas sugerem ainda que a relação teoria-prática almejada pelo licenciando se daria na forma de uma incorporação de algo externo - a teoria -, que seria um balizador da ação docente, e não como um aspecto constitutivo de sua subjetividade e ação. É na condição de aluno daqueles professores que "falharam" e de estudante das disciplinas de formação que ele critica a prática de seus professores.

Ao exercer a regência docente, nos Estágios Supervisionados, vive a condição de professor, ao mesmo tempo reconhecendo e estranhando, em sua experiência, certos aspectos que lhe eram familiares quando se encontrava no papel de estudante da Educação Básica, do outro lado da classe, ou como estudante de licenciatura, como um observador externo da relação professor-aluno. Agora, é na condição de professor que tal experiência ganha um significado.

[Comentando a apresentação de trabalhos pelos alunos do ensino fundamental]: [...] enquanto os alunos estavam lá em cima apresentando seus trabalhos, os demais estavam prestando atenção neles, certo? Claro que não, os outros estavam muito mais preocupados em estudarem/decorarem o trabalho deles a ouvirem o trabalho dos outros. Na verdade, isso me fez.pensar como certas coisas não mudam, independentemente de ser da sétima série, do ensino médio ou da faculdade. Sim, até hoje fazemos isso (e claro que me incluo muitas vezes no time, infelizmente) [...]. Nesses momentos em que nos fechamos na nossa redoma, no nosso mundinho particular, impedimos também a troca de conbecimentos, a possibilidade de aprendermos algo novo, interessante, uma curiosidade de um assunto em voga, por que não? $\mathrm{Ou}$, às vezes, podemos até saber todo o conteúdo que a pessoa na frente está 'ensinando', mas podemos aprender com ela uma maneira diferente de passá-la adiante. [...] Sem contar que as pessoas na frente percebem que não estamos prestando atenção nelas. E isso desperta nelas um sentimento de fracasso, de desânimo muito grande, afinal, elas disponibilizaram tempo e dedicação, mesmo sendo pouco ou muito, não importa, para preparar o que elas estão apresentando na frente. E não ter uma pessoa para prestigiar e reconhecer esses esforços é realmente decepcionante. E nesse momento percebi como é estar do outro lado, no lado da frente. E percebi que durante 
toda minha vida escolar, acadêmica, reclamava do professor que me chamava atenção quando estava conversando. Quando, na verdade, hoje, estando na pele dele, compreendo que ele tem lá suas razões, que, por sinal, são bem fortes. [Sabrina, ESEC]

O licenciando, então, se permite viver a experiência, no sentido apontado por Larrosa (2011), que envolve um estranhamento e uma familiaridade que ressignificam aquela busca de técnicas e métodos cujo domínio julgava que o tornariam um bom professor. Reconhece que a possibilidade de tornar-se o professor não é proporcionada por um conjunto de soluções externas a si mesmo, mas que envolve, também, uma implicação pessoal. Uma reflexão a partir de um outro lugar, proporcionado pela experiência.

Talvez.por ser nova e não ter muito ritmo para dar aulas e prepará-las anteriormente, senti que essas 40 horas de regência foram bem puxadas. Muitas vežes me coloquei no lugar de uma professora e pensava "eu estou morta com 40 horas de regência divididas com minha dupla ainda por cima, imagina a vida mesmo de um professor que fica 40 horas por semana durante o ano inteiro. [Sabrina, ESEC]

A narrativa sobre a docência em estágio também abre a possibilidade de uma outra leitura sobre a condição social da profissão docente. Se antes essa leitura era atravessada pelas disciplinas formativas e por discursos sociais - da imprensa, da família, da novela... - a respeito dessa condição, agora ela é perpassada pela experiência pessoal do sujeito que narra.

Cansaço... Essa foi uma palavra que me acompanhou durante todo o periodo da escola. Foi um cansaço físico, mental e energético, fiquei impressionada em como as crianças são sugadoras de energia. Ao final do estágio só conseguia pensar em como os professores conseguem dar tantas aulas durante tanto tempo, e às vez̨es uma vida toda dedicada ao ensino. Ai entendi que os professores cansam e assim nem sempre conseguem manter as aulas tão atrativas para os alunos, a professora Tânia me pareceu cansada. Não só pareceu cansada, mas de fato estava, digo pelos cochilos que frequentemente tirava durante minhas aulas. [Sandra, ESEC]

Já não escutamos mais um sujeito que analisa uma "experiência em geral" de um professor, mas aquele que padece uma experiência "de um modo único, singular, particular, próprio” (LARROSA, 2011, p. 7). A crítica dá lugar a uma compreensão empática, que passa, necessariamente, pela experiência.

\footnotetext{
${ }^{3}$ Os nomes são fictícios.
} 


\section{Considerações finais}

A reflexão proporcionada pelas narrativas é, em certo sentido, um exercício de leitura que os licenciandos fazem dos acontecimentos de sua formação que, ao mesmo tempo, visa a escrita de um texto endereçado a outro. Se encarada como experiência no sentido proposto por Larossa $(2011$, p. 10), a leitura de sua da realidade pelo sujeito que narra permite o acontecimento das três características enunciadas pelo autor: (1) "a experiência é uma relação com algo que não sou [...]”; (2) “[...] a experiência é uma relação em que algo tem lugar em mim..." e "[...] minha relação com o texto [...] é de condição reflexiva, volta para dentro, subjetiva, que me implica no que sou, que tem uma dimensão transformadora, que me faz outro do que sou"; e (3) "a experiência é algo que passa de mim a outro e de outro a mim. E nesse passa, tanto eu como o outro, sofremos alguns efeitos, somos afetados".

O primeiro aspecto já se revela nas narrativas sobre o reencontro dos estudantes com o professor e sua prática. Reencontro que possui uma dimensão de estranhamento, na medida em que é em outro lugar, o de professor em formação, que ele chega novamente à escola. E é deste outro lugar, novo, que ele lê e narra sua experiência. No próprio exercício de refletir e narrar, ele pode reconhecer tal experiência como algo que se passa dentro de si, ainda que proporcionada pelo encontro com o que lhe é externo. Chegamos, assim, ao segundo aspecto. Finalmente, porque é proporcionado por este encontro com o outro (a escola, seus alunos, seus professores e colegas), o exercício de leitura e narrativa dos acontecimentos é, também, um exercício de encontro com a alteridade.

Vemos, assim, que a relação teoria-prática atravessada pela experiência é mais do que uma leitura de uma experiência passada à luz da teoria. Aqui a reflexão pela narrativa se dá enquanto o sujeito está vivendo a experiência, e permite que, também, ressignifique vivências anteriores.

Outro aspecto evidenciado pelas narrativas dos estudantes aqui apresentadas é seu valor como método de pesquisa sobre o percurso formativo dos licenciandos, o que implica reconhecer a importância da subjetividade como categoria analítica, em estudos sobre formação. Ao mesmo tempo, tais narrativas podem vir a ser, elas mesmas, uma via de acesso, pelos licenciandos, a esses aspectos subjetivos que também compõem sua formação.

\section{Referências}

BUENO, B. O. O método autobiográfico e os estudos com histórias de vida de professores: a questão da subjetividade. Educação e Pesquisa, São Paulo, v. 28, n. 1, p. 11-30, 2002. Disponível em: <http://www.scielo.br/pdf/ep/v28n1/11653.pdf >. Acesso em: 4 nov. 2014.

CUNHA, M. I.; CHAIGAR, V. A. M. A dimensão da escrita e da memória na formação reflexiva de professores: dois estudos em diálogo. In: FERREIRA, M. O. V.; FISCHER, B. T. D.; PERES, L. M. V. (Org.). Memórias docentes: abordagens teórico-metodológicas e experiências de investigação. São Leopoldo: Oikos; Brasília: Liberlivro, 2009. p. 119-140. 
Gastal, M. L. A.; Avanzi, M. R.

FERRAROTTI, F. Sobre a autonomia do método biográfico. In: NÓVOA, A.; FINGER, M. (Org.). O método (auto)biográfico e a formação. São Paulo: Paulus, 2010. p. 19-57.

FINGER, M. As implicações socioepistemológicas do método biográfico. In: NÓVOA, A.; FINGER, M. (Org.). O método (auto)biográfico e a formação. São Paulo: Paulus, 2010. p. 119-128.

GALVÃO, C. Narrativas em educação. Ciência \& Educação, Bauru, v. 11, n. 2, p. 327-345, 2005. Disponível em: <http://www.scielo.br/pdf/ciedu/v11n2/12.pdf>. Acesso em: 04 nov. 2014.

GASTAL, M. L. et al. Da montanha à planície: narrativas e formação de professores de ciências e biologia. Revista da SBEnBIO, São Paulo, v. 3, p. 1252-1260, 2010.

JOSSO, M. C. Experiências de vida e formação. Natal: EDUFRN; São Paulo: Paulus, 2010a.

Da formação do sujeito ao sujeito da formação. In: NÓVOA, A.; FINGER, M.

(Org.). O método (auto)biográfico e a formação. Natal: EDUFRN; São Paulo: Paulus, 2010b. p. 59-79.

LARROSA, J. La experiencia de la lectura: estudios sobre literatura y formación. 2. ed. México: Fondo de Cultura Económica, 2003.

. Experiência e alteridade em educação. Reflexão \& Ação, Santa Cruz do Sul, v. 19, n. 2, p. 4-27, 2011.

MIZUKAMI, M. G. N. et al. Escola e aprendizagem da docência: processos de investigação e formação. São Carlos: EDUFSCAR, 2002.

NÓVOA, A. (Org). Vidas de professores. Porto: Porto Editora, 1995.

PIMENTA, S. G. Professor reflexivo: construindo uma crítica. In: PIMENTA, S. G.;

GHEDIN, E. (Org.). Professor reflexivo no Brasil: gênese e crítica de um conceito. 3. ed. São Paulo: Cortez, 2008. p. 17-52.

PINEAU, G. As histórias de vida em formação: gênese de uma. Educação e Pesquisa, São Paulo, v. 32, n. 2, p. 329-343, 2006.

TARDIF, M. Saberes profissionais dos professores e conhecimentos universitários: elementos para uma epistemologia da prática profissional dos professores e suas consequências em relação à formação para o magistério. Revista Brasileira de Educação, Brasília, n. 13, p. 5-24, 2000.

Artigo recebido em 05/06/13. Aceito em 10/06/14. 